\title{
Community Garden Initiatives Addressing Health and Well-Being Outcomes: A Systematic Review of Infodemiology Aspects, Outcomes, and Target Populations
}

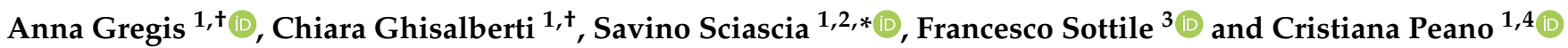 \\ 1 UNESCO Chair in Sustainable Development and Territory Management, University of Turin, 10100 Turin, \\ Italy; anna.gregis@unito.it (A.G.); chiara.ghisalberti@unito.it (C.G.); cristiana.peano@unito.it (C.P.) \\ 2 Center of Research of Immunopathology \& Rare Diseases, Nephrology \& Dialysis, S. Giovanni Bosco \\ Hospital, Department of Clinical and Biological Sciences, University of Turin, 10100 Turin, Italy \\ 3 Department of Architecture (DARCH), University of Palermo, VialedelleScienze, Edificio 14, 90145 Palermo, \\ Italy; francesco.sottile@unipa.it \\ 4 Department of Agricultural, Forest and Food Sciences (DISAFA), University of Torino, Largo Paolo Braccini 2, \\ Grugliasco, 10095 Torino, Italy \\ * Correspondence: savino.sciascia@unito.it; Tel.: +39-011-240-2051 \\ + These Authors equally participated to this study.
}

\section{check for} updates

Citation: Gregis, A.; Ghisalberti, C.; Sciascia, S.; Sottile, F.; Peano, C. Community Garden Initiatives Addressing Health and Well-Being Outcomes: A Systematic Review of Infodemiology Aspects, Outcomes, and Target Populations. Int. J. Environ. Res. Public Health 2021, 18, 1943. https://doi.org/10.3390/ ijerph18041943

Academic Editor: Paul B. Tchounwou

Received: 7 January 2021

Accepted: 5 February 2021

Published: 17 February 2021

Publisher's Note: MDPI stays neutral with regard to jurisdictional claims in published maps and institutional affiliations.

Copyright: (C) 2021 by the authors. Licensee MDPI, Basel, Switzerland. This article is an open access article distributed under the terms and conditions of the Creative Commons Attribution (CC BY) license (https:// creativecommons.org/licenses/by/ $4.0 /)$.

\begin{abstract}
Previous research has suggested that activities such as community gardens could offer a wide range of health benefits. The aim of the article is to systematically review the available literature to analyse the magnitude of the phenomenon, the geographical distribution, and the main characteristics in terms of health outcomes and target populations. The search addresses the question whether the activity in community gardens improves health and well-being outcomes of individuals. From the total amount of 7226, 84 selected articles showed that:(1) up to 50\% are published by U.S. universities or institutions; (2) up to $44 \%$ of the studies considered "community gardens" as the main activity of the research focus; (3) one-third of the studies included adults; (4) almost 25\% of the studies used "general health" as the main outcome when investigating the benefits of community gardens; (5) the percentage of studies that achieved their outcomes was heterogeneous among the different health dimensions. In conclusion, while a certain degree of heterogeneity in the used definition and outcome still exist, community gardens may be a viable strategy for well-being promotion in terms of psychological, social, and physical health and may be considered as an innovative urban strategy to promote urban public health.
\end{abstract}

Keywords: community gardens; health promotion; well-being; urban greenspace; public health

\section{Introduction}

With the world population rapidly increasing, it is estimated that up to $70 \%$ of people will live in urban spaces in the next threedecades [1]. This trend has enormous implications for both human health and environmental impacts. Hence, urban policies supporting the promotion of sustainable and healthy lifestyles are urgently needed [2].

Previous research has suggested that activities such as community gardens could offer a wide range of health benefits. Indeed, across Europe, there are around three million individual allotment gardens. These kinds of initiatives are now spreading not only in Europe but all around the world [3].

The phenomenon of urbanization has been associated with negative impacts on human health, such as mental illness and obesity [4]. In this regard, a growing body of research is suggesting that the availability of urban green space close to the home is associated with longevity and general improvement on health in the users [5]. Gardening might play a key role not only in preventive health, both in urban and suburban areas, but it is becoming an important policy strategy for "sustainable urban development" [6]. 
Sustainable urban development encompasses several urban settlement theoretical frameworks, including the concepts of "Sustainable City", "Low-Carbon City", "Healthy City", "Livable City", "Smart City", and "Green City" [7].

In a recent of analysis, Hui-Ting Tang and Yuh-Ming Lee stated that sustainable urban development aims "to achieve maximum development with minimum resource consumption and environmental impact to ensure the well-being of both humans and the Earth" [8].

Although community gardens are becoming more and more prevalent, there is still a lack of consensus when referring to some definitions. The terminology of "community garden" is probably the most diffused and can be considered as an umbrella for all the other typologies. It is conceived as a green space where individuals grow vegetables and food in a common and collective way [9]. This last aspect of the management of food growing marks a difference from the allotment gardens, instead considered as "a parcel of land acquired by individuals and/or family via a lease or rent for personal usage" [10]. Gardens can be found in many different areas, from parks in cities to countryside areas. The aims of the gardens can also vary. For our analysis, we chose to apply the terminology of "community gardens". However, significant differences from the chosen terminology will be commented on when present.

\section{What Is the Link between Human Health and Well-Being and Community Gardens?}

More than half a century ago, the World Health Organization (WHO) defined health as "a state of complete physical, mental and social well-being and not merely the absence of disease or infirmity" [11]. Although this definition has been debated for being overly inclusive and hard to achieve [12], it has the merit to broaden the medical definition of health beyond the simple absence of disease. For the purpose of our analysis, we applied the following definitions for health and wellbeing. Health is a state of being, whereas well-being aims to integrate mental health (mind) and physical health (body) resulting in more holistic approaches to disease prevention and health promotion [13].

The 'exposure-effect' of urban gardening on health and well-being has been largely investigated [14-18]. Available studies have shown that the incidence of various chronic and non-communicable diseases, including depression and anxiety symptoms, diabetes, and obesity, is affected by the availability and size of green spaces [19].

Since community gardens are considered as an activity conducted in a green space, they might be part of a multi-component intervention that involves many activities: gardening and physical activity (PA), using and enjoying a green space, food production and consumption, social interaction. This multiple set of activities has been shown to enhance the local environment and the community, promote general health and wellbeing [20]. Hence, gardening delivers benefits across the physical, psychological, and social dimensions of health [21].

From a social point of view, several research studies have demonstrated that gardening improves social ties, enhances community capacity and knowledge [22]. By proving a variety of emotional and social processes, gardening positively affects people's wellbeing [23]. Other studies demonstrate that gardening has a clear relationship between stress and anxiety reduction, with evident improvements in mood [24], self-esteem, and satisfaction $[25,26]$. These benefits are linked to the social, psychological, and emotional sphere of an individual practicing gardening.

To offer a reliable overview, many activities have assessed the impacts in terms of social and psychological benefits, including dietary patterns, mostly investigating fruit and vegetable $(\mathrm{F} \& \mathrm{~V})$ consumption and dietary behaviors [26-30]. Most of them are linked to school gardens or activities targeting children. An interesting study proved that gardeners and their children were more willing to eat foods if they picked themselves [23].

The possibility that gardening offers individuals the opportunity for physical activity needs to be emphasized [28]. Indeed, especially during spring and summer seasons, research highlights a significant increase of physical activity as a result of the multiple tasks 
required, such as picking, growing, and daily management works, potentially leading to a health benefit (e.g., in terms of metabolic and cardiovascular conditions) [28]. In line with this information, Wood et al. [29] have found that beneficial health effects related to gardening can be observed with less than 30 min of daily physical activity. A significant result is a special legislation proposed and approved recently by the Danish government, which gives allotment gardens a permanent status, thus enhancing healthy living policies [30].

While the above-mentioned aspects have been supporting a promising role in the implementation of community gardens, still a degree of heterogeneity exists when referring to the type of urban gardening, outcomes of health impact, and included populations [31,32]. Indeed, an analysis of qualitative and quantitative aspects of the impact of community gardens on human health has the potential to guide future policy strategies and areas of future development. However, a comprehensive analysis investigating the granularity of the current scenarios is still missing [33].

In this study we aimed to systematically review the available literature investigating the impact of the community garden on human health and well-being, analyzing the magnitude of the phenomenon, the geographical distribution, and the main characteristics in terms of health outcomes and target populations.

\section{Research and Methods}

A detailed literature review has been developed a priori to identify articles that reported findings on health outcomes in individuals exposed to community gardening activity to reply to the Population/Patient/Problem, Intervention, Comparison, Outcome (PICO) question: does the activity in community gardens improve health and well-being outcomes of individuals?

Considering the topic of the research, the team identified two databases for the search: Scopus and PubMed. Both qualitative and quantitative studies have been included. The search included the international literature, which is published in English, from 2010 to 2020.The search was obtained by the string "health" AND "garden".

Inclusion criteria of the studies included: (a) individual exposed to community gardening activity (b) the presence of health outcomes among the effects of the exposure (c) original research.

For this review, the terminology community gardening was used through our search and possible alternative nomenclature screened, with the understanding of defining community gardening as all the activities that entail foods and vegetable cultivation by individuals, with communal or individual management. It includes all types of "community gardens" such as school gardens, specific policy programs, prison gardens, as well as individual initiatives such as household gardens. The selection included articles that were assessing health outcomes linked to "community gardens" also in case this activity was not the only one involved in the study. No differences in the inclusion have been done concerning the settlement of the community gardens (urban areas or rural). Finally, the activities included in the study address individuals of any age and belonging to any cases, even specific cases such as prisoners or cancer survivors. In terms of health outcomes, authors considered all types of assessment, self-rated evaluations by gardeners or assessed by researchers, which showed impacts related to health (e.g., cardiovascular outcomes, metabolic conditions, body mass index, diet patterns, psychological impact) and well-being (social factors).

Exclusion criteria included: (a) all studies not meeting the inclusion criteria were excluded from this review. (b) literature reviews or commentary articles. (c) studies that assessed only dietary intake (e.g., fruit and vegetable consumption). The approach used was to review a minimum of 10 percent of titles, abstracts, and full text results, to offer an overarching critique of the strengths and limitations of existing health and community garden studies.

We attempt an infodemiology approach-defined as a strategy to investigate the distribution and determinants of information in an electronic medium, specifically the 
Internet-when analyzing the distribution and determinants of information in available publications, with the ultimate aim to inform public health and public policy.

To quantify the potential benefit of the community garden on the different dimensions of health and well-being, a radar chart analysis was applied. Chi-Square test was used to analyze the discrete variable. Microsoft excel 2010 (Microsoft, Redmond, Washington, DC, USA) was used to draw the radar plot. $p$-value is considered to be significant if less than 0.05 .

\section{Results}

The search obtained by the string "health" AND "garden", identified 4800 articles on PubMed and 2426 on Scopus. Among these, the articles available in both databases were excluded. From the total amount of 7226, the present analysis focuses on the 84 selected articles meeting the inclusion criteria and pertinent for this analysis. As shown in Figure 1, there is a growing interest in the topic, as supported by the increasing number of published studies over the last 10 years in both Scopus and PubMed. However, the trend seems more evident when analyzing data from PubMed.

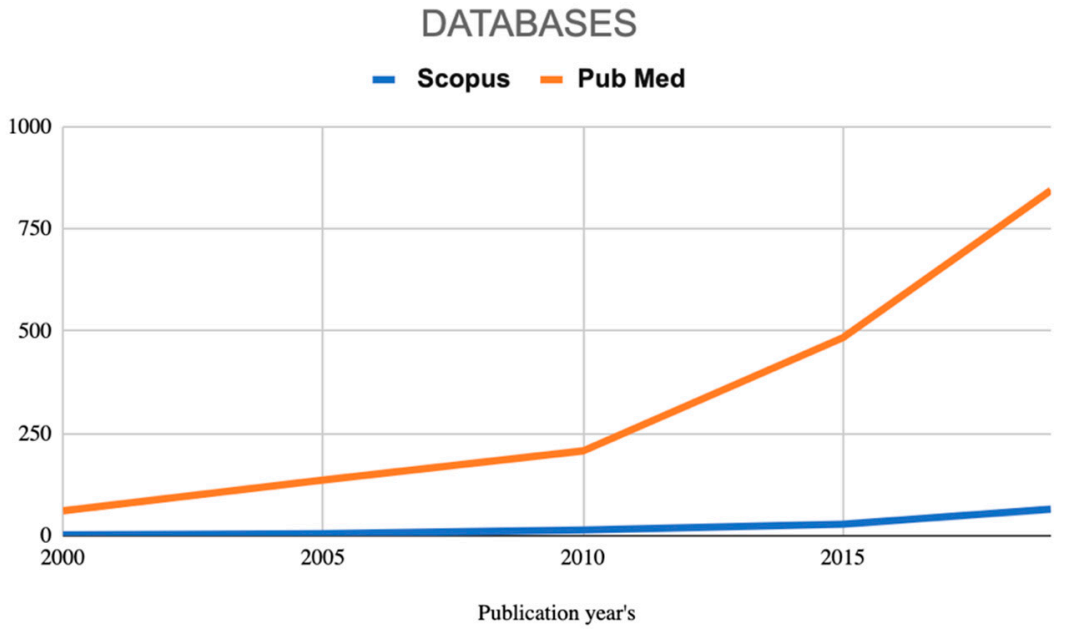

Figure 1. PubMed and Scopus publication trend between 2000 and August 2020.

Out of 84 analyzed studies, half (50\%) are published by U.S. universities or institutions, followed by the United Kingdom (13,1\%). Up to $12 \%$ of the published studies are the results of international collaborations. No significant difference was observed when comparing the location of researchers/institutions and the areas where the research was conducted (Figure 2). 


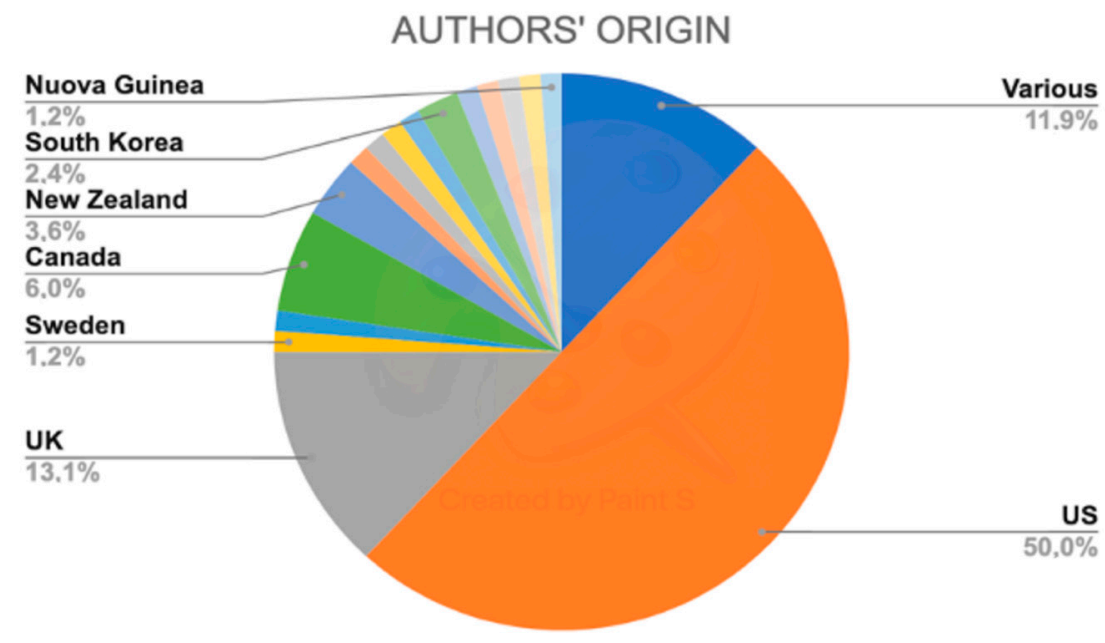

(a)

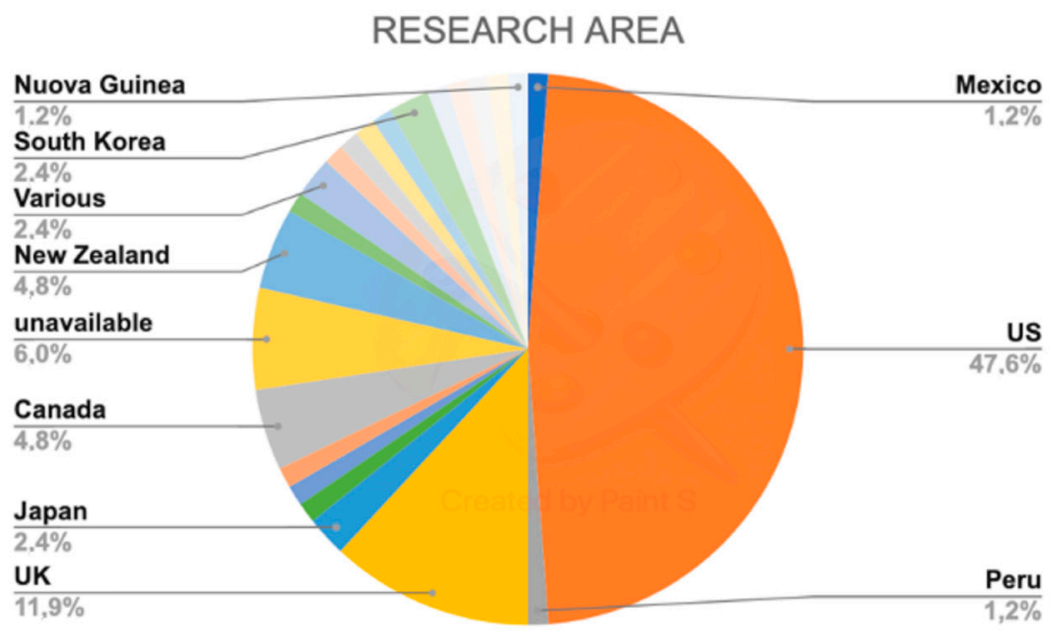

(b)

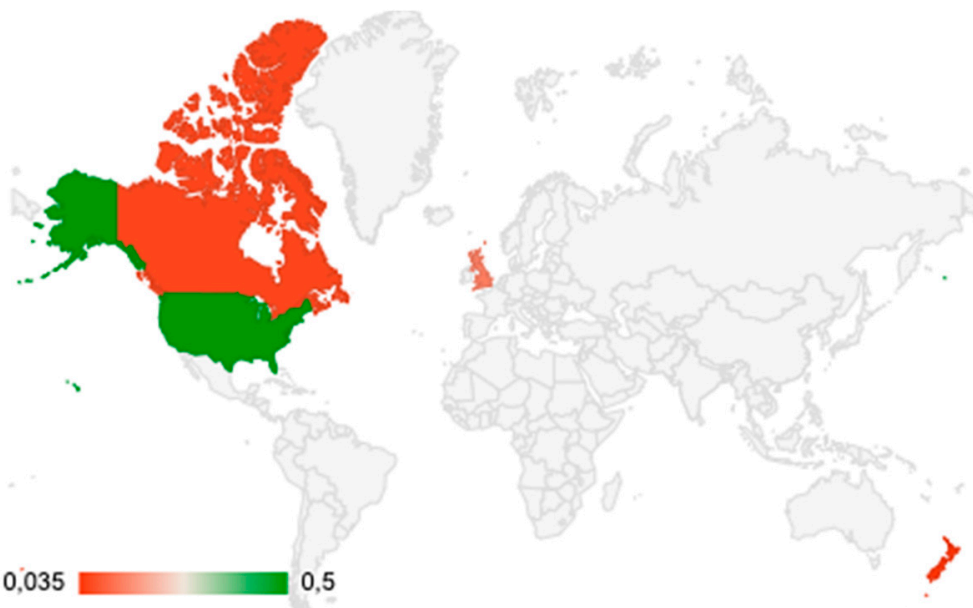

(c)

Figure 2. (a) Origin of the publications' authors; (b): Geographical areas of research; (c): Geographical interest of the research topic. 
Participating in the activity of a community garden could represent the main focus of the research. Alternatively, being part of the activity of a community garden could be part of a composite intervention to improve health/well-being through other activities (e.g., change in diet, change in PA, etc.). In detail, we found that up to $44 \%$ of the studies considered "community gardens" as the main activity of the research focus (Figure 3a). Almost one-third of the research, instead, gardening was considered as part of multiple activities, (labeled as "complementary), to assess whether these practices might confer any health benefits. Up to $10 \%$ of the studies focused on household gardening. Finally, around $8 \%$ of the total studies focused on both horticultural therapy and school gardens.

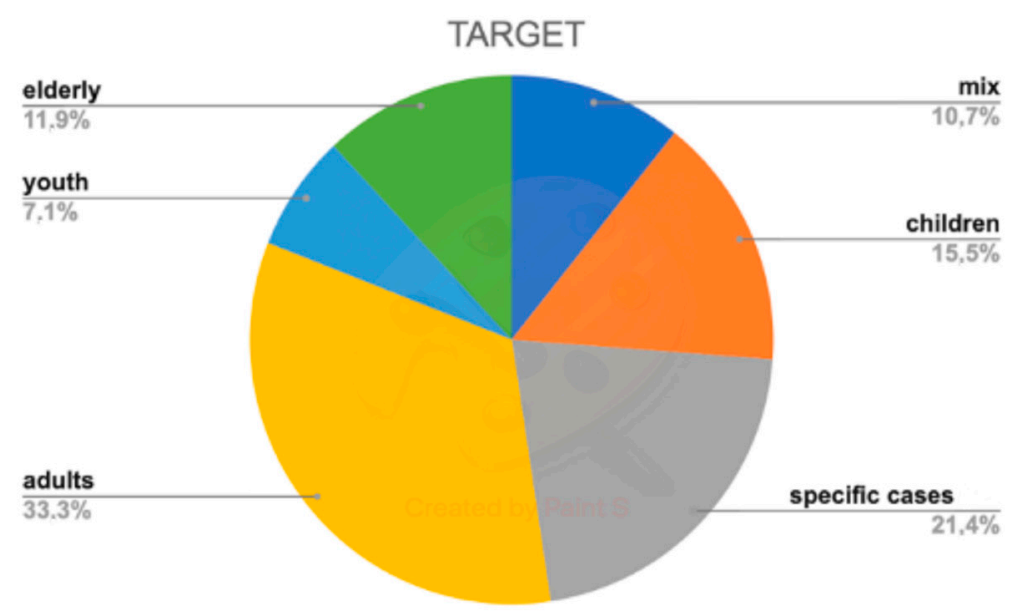

(a)

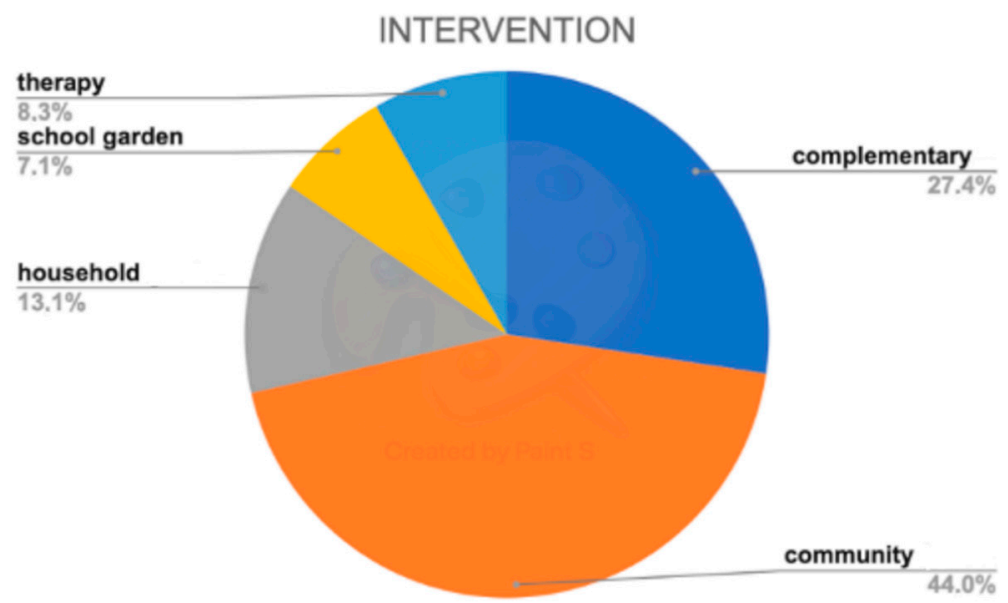

(b)

\begin{tabular}{|l|c|}
\hline Target (mix 10.7\%) & N. \\
\hline adults and children & 6 \\
\hline young and adults & 3 \\
\hline
\end{tabular}

(c)

Figure 3. (a) Type of activity/intervention; (b)Garden-based activities target to different groups. (c) details on the mixed age-groups.

When stratifying results for the studied population, results are shown in Figure $3 b$. One-third of the studies included adults; one-fifth is related to specific cases such as prisoners and individuals affected by different diseases, with cancer the most represented. Relevant interest is shown in children and youth and more than one on ten is addressed to the elderly. Finally, more than $10 \%$ of the studies investigated mixed groups, with 6 studies 
focusing on adults and children (most of the time mothers) and just 3 focus on youth and adults (Figure 3b,c).

\section{Health Outcomes}

Figure 4 shows the distribution of different outcomes measured in each study.

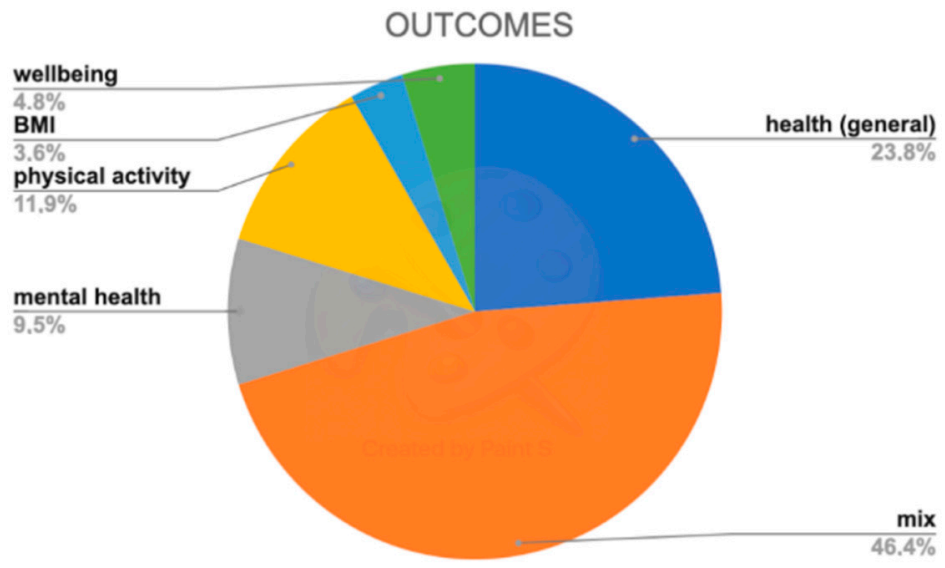

Figure 4. Different outcomes distribution grouped by main categories.

Almost $25 \%$ of the studies used "general health" as the main outcome when investigating the benefits of community gardens. Around 10\% reported benefits both in terms of mental health and physical activity. A marginal amount of the studies evaluated the impacts in terms of body mass index (BMI) and general "well-being". It is worth noting that up to $46 \%$ of the studies used composite outcome definitions when evaluating the impact of community gardening on health and wellbeing. Table 1 provides the details on the different indicators selected for the assessment of the impacts generated by the garden-based activity in studies with composite outcome definition.

When attempting to quantify the potential benefit of the community garden on the different dimensions of health and well-being, a radar chart analysis was performed (Figure 5).

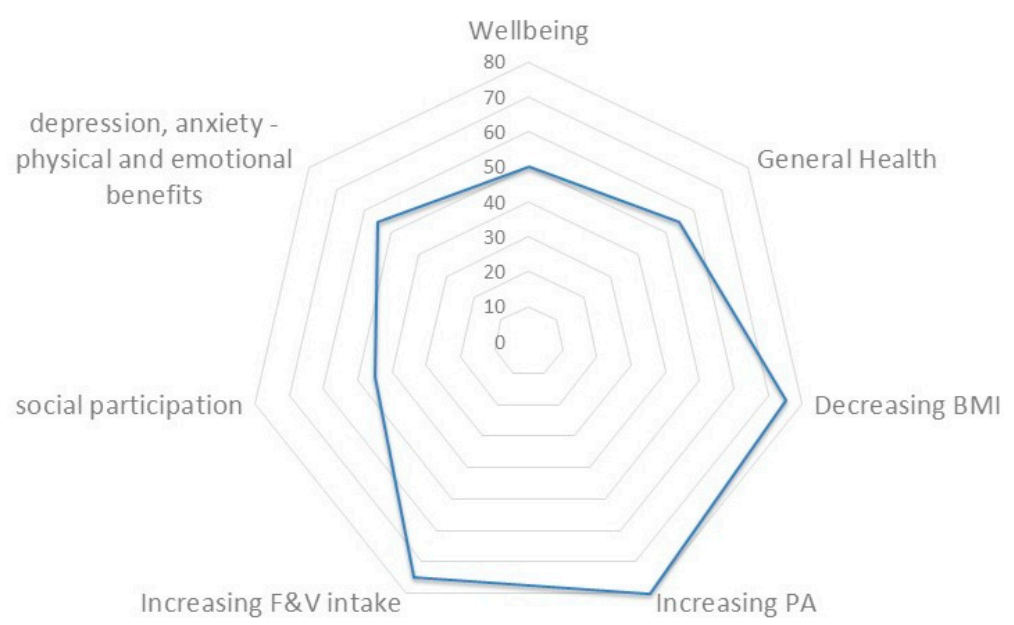

Figure 5. Spider chart providing a graphical representation of the percentage of studies meeting their outcomes subgrouping them for analyzed health dimensions. 
Table 1. Details of the main outcomes shown in studies with composite outcome definition (46.4\% of the total).

BMI Secondary outcomes: child BMI, and

$\mathrm{F} \& \mathrm{~V}$ intake and PA adult hand strength, self-reported physical and mental health, diabetes control and food security.

\begin{tabular}{cc}
\hline $\begin{array}{c}\text { Dietary intake, mental and physical health, } \\
\text { sense of community and social support, } \\
\text { long-term maintenance }\end{array}$ & $\begin{array}{c}\text { Participant accrual, retention, and satisfaction } \\
\text { rates. Secondary outcomes (i.e., vegetable } \\
\text { consumption, physical activity, performance } \\
\text { and function, anthropometrics, biomarkers, } \\
\text { and health-related quality of life) }\end{array}$ \\
\hline $\begin{array}{c}\text { weight status, vegetable and sugar sweetened } \\
\text { beverage consumption, PA and sedentary } \\
\text { behavior }\end{array}$ & health and personal growth, mental well-being \\
\hline $\begin{array}{c}\text { mental health and wellbeing } \\
\text { sense of community and social support; } \\
\text { long-term maintenance }\end{array}$ & F\&V consumption, waist circumference \\
\hline mood and general health & health and emotional well-being \\
\hline $\begin{array}{c}\text { dietary intake, PA, anthropometrics, blood } \\
\text { values, and skin carotenoids }\end{array}$ & quality of life and emotional well being \\
\hline health, well-being and PA & nutrition and BMI \\
\hline $\begin{array}{c}\text { PA, height, and weight, dietary habits. } \\
\text { benefits }\end{array}$ & F\&V intake, PA quality-of-life, and physical \\
function
\end{tabular}

Children's length/height-for-age z-scores,

micronutrient status, dietary intake, dietary

diversity and other indicators of child growth, development and morbidity

BMI, waist circumference, blood pressure,

hemoglobin A1c, vitamin D, low-density

lipoprotein cholesterol, and household food

Diabetes security

\begin{tabular}{cc}
\hline chronic stress & dietary intake and obesity risk \\
\hline $\begin{array}{c}\text { psychological distress and social participation } \\
\text { mental health, cognitive functioning and } \\
\text { physical health }\end{array}$ & emotional well-being, physical health. \\
\hline $\begin{array}{c}\text { PA, mental health, and stress management; } \\
\text { weight, diabetes }\end{array}$ & cognitive ability \\
\hline health and well-being & dietary intake, BMI \\
\hline $\begin{array}{c}\text { dietary behaviors, PA, mental health, and } \\
\text { social relationships }\end{array}$ & food security and well-being \\
\hline cognitive and nutrition & \\
\hline
\end{tabular}

PA, physical activities; F\&V, fruit and vegetables; BMI, body mass index.

The data length of each spike is proportional to the percentage of studies meeting their outcomes sub-grouping studies according to the used outcome. Studies with composite outcomes were computed separately taking into account the different results when provided. 
Figure 5 showed that the percentage of studies meeting their outcome was heterogeneous among the different health dimensions, with reducing the BMI and increasing physical activity and consumption of fruit and vegetables, the dimensions more often observed in studies achieving their outcomes when compared to the other groups $(p<0.05)$.

\section{Discussion}

In line with the urban sustainable development concept, urban gardening is a key player of a trend towards more green areas in cities, consumption of organic, locally grown food, and a closer link with one's own living environment [8].

Our analysis showed that there is an overall increased interest in the field of community gardening, especially in some areas such as U.S. and U.K. Interestingly, while several initiatives on community garden are well established in European cities [34], this interest did not seem to be paralleled with scientific publications. This aspect is worth mentioning as it can suggest some degree of mismatch between initiatives operating in real-life settings and academic activities. Similarly, while the U.S. and U.K. are both in the list of top countries by number of scientific and technical journal articles, China has displaced the U.S. as the world's top research publisher in science and engineering [35]. However, this trend was not observed in our analysis. Besides, while it was out of the scope of our analysis to investigate the differences in retrievable studies on the topic when comparing Scopus and PubMed, one could speculate that PubMed might index journals in the field of medicine not necessarily included in Scopus.

While the associations between green space and human health have been summarized in several frameworks over the last years [36], we aimed to place these 'exposure-effect' relations in the broader context of urban sustainable development. In fact, despite the increasing interest of urban community gardens, planning guidelines concerning specific objectives and activities, target populations, and, more critically, outcomes applied to investigate potential benefit on health and well-being are still debated.

As expected, we found a marked level of heterogeneity in terms of those aspects. Indeed, also the terminology used to refer to community gardening present a marked level of variability, potentially impacting the extrapolatable potential of the results. Challenges have been encountered when trying to systematize the health and well-being outcomes and impacts of garden-based interventions computing together results from different studies. Studies coming from different disciplinary approaches offer inconsistent and different outcome measurements. For instance, studies investigating specific target groups such as indigenous people and tribes [31] aimed to assess health using wider and multidimensional indicators. Conversely, some other studies used focuses on disease-specific indicators that might be applicable only in some specific settings [32]. An integrated framework able to assess the different indicators in a harmonized way should be warranted in future research to assess the impact of community activities such as gardening taking into account different dimensions.

Our analysis highlights some criticism to be addressed before planning future research in the field.

First, the duration of the interventions varied widely across the studies. Nonetheless, by assessing the frequency and the duration of the garden-based intervention some authors suggested those variables did not significantly affect the potential benefit on participants health [29]. This observation is relevant as it might suggest that even a short-term intervention might lead to some health benefits, making community gardening activity more easily implementable into daily urban routines.

Secondly, the type of intervention and seasonality. It is evident that seasonality affects the overall development of community gardening and potential outcomes need to take this aspect into account [33].This is particularly relevant, for instance, when outcomes such as physical activity are analyzed.

Thirdly, the reported studies vary widely in terms of methodology. In the majority of the studies, a control group is not reported, creating limitations and introducing bias, 
so reducing the possibilities to detect possible differences. When available [25], control groups are represented by non-gardeners or individuals living in the same neighborhood as gardeners.

Additionally, a marked variability across studies is represented by heterogeneity in data collection, with many studies being based on self-reporting [33]. While this method can increase participation in terms of sample size, it might lack reproducibility.

Despite the already mentioned heterogeneity, some considerations are worth noting. Firstly, our analysis showed that reducing the BMI, increasing physical activity, and fruit and vegetables intake are the dimensions more often observed in studies achieving their outcomes when compared to the other groups. On the one hand, these observations might be not surprising, as those indicators might be more easily quantifiable when compared to other social or emotional dimensions. On the other hand, these findings might pave the way for future research providing the basis and rationale for future reproducible and scalable approaches.

One novelty of our analysis is based on the comparison of the target populations when focusing on age. Some studies [33] targeted different age groups, including the elderly. Some heterogeneity in terms of impacts on health, especially in terms of mental health, cognitive functioning, and physical health was found in studies in which a comparison of results across age groups was possible [37]. This concept is further supported in an analysis specifically designed to demonstrate the therapeutic effects of horticulture in older adults [38]. Thereby, the authors suggest that it is important to consider the multiple demographic variables which may affect the results of the research.

When focusing on the impact of community gardening on children, our analysis reported that the majority of the studies focused on the implementation of school gardens or specific garden-based initiative [39]. Some of the included studies considering gardening as a complementary activity part of wider programs also including food education. These studies [38-40] mainly focused on dietary intake, specifically fruit and vegetable consumption. It is interesting to notice that studies are consistent when analyzing outcomes related to different age groups: the major assessment in elderly population is focused on physical activity and mental health; conversely, in children, the evaluation is mainly based on dietary patterns.

\section{Conclusions}

The present study seems the first systematic attempt to assess whether community gardens provide health and well-being benefits. Despite the relevant degree of variability, our results are consistent in showing a growing interest in community gardening as a potential tool to improve health and well-being outcomes across different group ages, geographical areas, target populations, and indicators.

All in all, community gardens may be a viable strategy for health promotion in terms of physical, social, and psychological dimensions and it may be considered a complementary urban strategy to promote urban public health [41,42].

Promoting and enhancing a coherent, systematic, and interdisciplinary impact assessment approach in community gardens will help actors and main stakeholders to design future policy strategies. Besides, an increase in green space in urban spaces may foster environmental sustainability and strengthen neighborhoods and community capacity and capital $[43,44]$. This is particularly true in an urban setting, with rates of obesity, air pollution, and cardio-vascular diseases increasing rapidly in the most populated areas. The identification of local-based solutions contributing to the improvement of public health is therefore highly needed. Furthermore, involving citizens in an engaging activity may enforce processes of community building, with the result of strengthened social ties.

Author Contributions: Writing-original draft preparation, A.G., C.G., S.S., F.S., and C.P.; writingreview and editing A.G., C.G., S.S., F.S., and C.P.; All authors have read and agreed to the published version of the manuscript. 
Funding: None.

Informed Consent Statement: Not applicable due to the nature of the study (systematic review of the literature).

Data Availability Statement: Available upon request to the corresponding author.

Conflicts of Interest: The authors declare no conflict of interest.

\section{References}

1. United Nations Department of Economic and Social Affairs. 2018 Revision of World Urbanization Prospects. Available online: https:/ / population.un.org/wup/ (accessed on 2 November 2020).

2. Tzoulas, K.; Korpela, K.; Venn, S.; Yli-Pelkonen, V.; Kaźmierczak, A.; Niemela, J.; James, P. Promoting ecosystem and human health in urban areas using Green Infrastructure: A literature review. Landsc. Urban Plan. 2007, 81, 167-178. [CrossRef]

3. Stephan, B.; Carl, F.; Johan, C. Social-ecological memory in urban gardens: Retaining the capacity for management of ecosystem services. Glob. Environ. Chang. 2010, 20, 255-265.

4. Lu, X.; Yuan, D.; Chen, Y.; Fung, J.C.H. Impacts of urbanization and long-term meteorological variations on global $\mathrm{PM}_{2.5}$ and its associated health burden. Environ. Pollut. 2020, 270, 116003. [CrossRef]

5. Maas, J.; Verheij, R.; De Vries, S.; Spreeuwenberg, P.; Schellevis, F.G.; Groenewegen, P.P. Morbidity is related to a green living environment. J. Epidemiol. Community Health 2009, 63, 967-973. [CrossRef] [PubMed]

6. Kingsley, J.Y.; Townsend, M.; Henderson-Wilson, C. Cultivating health and wellbeing: Members' perceptions of the health benefits of a Port Melbourne community garden. Leis. Stud. 2009, 28, 207-219. [CrossRef]

7. Cities of Tomorrow. Challenges, Visions, Ways Forward. Available online: https://ec.europa.eu/regional_policy/sources/ docgener/studies/pdf/citiesoftomorrow/citiesoftomorrow_final.pdf (accessed on 3 February 2021).

8. TingTang, H.; Lee, Y.M. The making of sustainable urban development: A synthesis framework. Sustainability $2016,8,492$. [CrossRef]

9. George, D.R.; Rovniak, L.S.; Kraschnewski, J.L.; Hanson, R.; Sciamanna, C.N. A growing opportunity: Community gardens affiliated with US hospitals and academic health centers. Prev. Med. Rep. 2015, 2, 35-39. [CrossRef]

10. Genter, C.; Roberts, A.; Richardson, J.; Sheaff, M. The contribution of allotment gardening to health and wellbeing: A systematic review of the literature. Br. J. Occup. Ther. 2015, 78, 593-605. [CrossRef]

11. WHO Remains Firmly Committed to the Principles Set Out in the Preamble to the Constitution. Available online: https: / / www.who.int/about/who-we-are/ constitution (accessed on 30 January 2021).

12. St Claire, L.; Watkins, C.J.; Billinghurst, B. Differences in meanings of health: An exploratory study of general practitioners and their patients. Fam. Pract. 1996, 13, 511-516. [CrossRef] [PubMed]

13. Well-Being Concepts. Available online: https://www.cdc.gov/hrqol/wellbeing.htm (accessed on 30 January 2021).

14. Bartłomiejski, R.; Kowalewski, M. Polish urban allotment gardensas' slow city' enclaves. Sustainability 2019, 11, 3228. [CrossRef]

15. Dubová, L.; Macháč, J. Improving the quality of life in cities using community gardens: From benefits for members to benefits for all local residents. GeoScape 2019, 13, 68-78. [CrossRef]

16. Tharrey, M.; Sachs, A.; Perignon, M.; Simon, C.; Mejean, C.; Litt, J.; Darmon, N. Improving lifestyles sustainability through community gardening: Results and lessons learnt from the J Are In Quasi-experimental study. BMC Public Health 2020, 20 , 1-13. [CrossRef]

17. Caneva, G.; Cicinelli, E.; Scolastri, A.; Bartoli, F. Guidelines for urban community gardening: Proposal of preliminary indicators forseveral ecosystem services (Rome, Italy). Urban For. Urban Green. 2020, 56, 126866. [CrossRef]

18. Triguero-Mas, M.; Anguelovski, I.; Cirac-Claveras, J.; Connolly, J.; Vazquez, A.; Urgell-Plaza, F.; Cole, H. Quality of life benefits of urban rooftop gardening for people with intellectual disabilities or mental health disorders. Prev. Chronic Disease 2020, $17,200087$. [CrossRef]

19. Beyer, K.M.M.; Kaltenbach, A.; Szabo, A.; Bogar, S.; Nieto, F.J.; Malecki, K.M. Exposure to neighborhood green space and mental health: Evidence from the survey of the health of wisconsin. Int. J. Environ. Res. Public Health 2014, 11, 3453-3472. [CrossRef]

20. Lucht, J.; Greever-Rice, T. Community Gardening-A Review of the Research Literature; Missouri: University of Missouri Cooperative Extension: Columbia, MO, USA, 2012.

21. Armstrong, D. A survey of community gardens in upstate New York: Implication for health promotion and community development. Health Place 2000, 6, 319-327. [CrossRef]

22. Alaimo, K.; Reischl, T.M.; Ober-Allen, J. Community gardening, neighborhood meetings and social capital. J. Community Psychol. 2010, 38, 497-514. [CrossRef]

23. Alaimo, K.; Beavers, K.W.; Crawford, C.; Hodges Snyder, E.; Litt, J.S. Amplifying health through community gardens: A framework for advancing multi component, behaviorally based neighborhood interventions. Curr. Environ. Health Rep. 2016, 3, 302-312. [CrossRef]

24. Thompson, R. Gardening for health: A regular dose of gardening. Clin. Med. (Lond). 2018, 18, 201-205. [CrossRef] [PubMed]

25. Masashi, S.; Cox, D.T.C.; Yuichi, Y.; Gaston, K.J.; Kiyo, K.; Keisuke, H. Health benefits of urban allotment gardening: Improved physical and psychological well-being and social integration. Int. J. Environ. Res. Public Health 2017, 12, 71. 
26. Ozer, E.J. The effects of school gardens on students and schools: Conceptualization and considerations for maximizing healthy development. Health Educ. Behav. 2006, 34, 846-863. [CrossRef] [PubMed]

27. Park, S.-A.; Shoemaker, C.A.; Haub, M.D. Physical and psychological health conditions of olde radults classified as gardeners or nongardeners. Hort. Sci. 2009, 44, 206-210. [CrossRef]

28. Lachowycz, K.; Jones, A.P. Green space and obesity: A systematic review of the evidence. Obes. Rev. 2011, 12, e183-e189. [CrossRef]

29. Wood, C.J.; Pretty, J.; Griffin, M. Acase-Control study of the health and well-being benefits of allotment gardening. J. Public Health 2015, 38, e336-e344. [CrossRef]

30. Daugbjerg, S.B.; Kahlmeier, S.; Racioppi, F.; Martin-Diener, E.; Martin, B.; Oja, P.; Bull, F. Promotion of physical activity in the European region: Content analysis of 27 national policy documents. J. Phys. Act. Health 2009, 6, 805-817. [CrossRef]

31. Ruakere, H.; Mihi, R.; Will, E. The role of Māori community gardens in health promotion: A land-based community development response by Tangata Whenua, people of their land. Glob. Health Promot. 2019, 26, 44-53.

32. Weltin, A.; Lavin, R.P. The effect of a community garden on HgA1c in diabetics of Marshallese descent. J. Community Health Nurs. 2012, 29, 12-24. [CrossRef] [PubMed]

33. VandenBerg, A.V.; van Winsum-Westra, M.; de Vries, S.; van Dillen, S.M.E. Allotment gardening and health: A comparative survey among allotment gardeners and their neighbors without an allotment. Environ. Health 2010, 9, 74. [CrossRef]

34. Urban Gardening in European Cities. Motives for Urban Community Gardening Using Examples of Birmingham City (UK) Available online: https:/ / www.urbanallotments.eu/fileadmin/uag/media/STSM/Short_Report_STSM_2014_PLESCHBERGER. pdf (accessed on 2 November 2020).

35. The Countries Leading the World in Scientific Research. Available online: https://www.weforum.org/agenda/2020/01/top-tencountries-leading-scientific-publications-in-the-world/ (accessed on 30 January 2021).

36. Hartig, T.; Mitchell, R.; de Vries, S.; Frumkin, H. Nature and health. Annu. Rev. Public Health 2014, 35, 207-228. [CrossRef]

37. Chan, H.Y.; Ho, R.C.M.; Mahendran, R.; Ng, K.S.; Wai-San Tam, W.; Rawtaer, I.; Tan, C.H.; Larbi, A.; Feng, L.; Sia, A.; et al. Effects of horticultural therapy on elderly' health: Protocol of a randomized controlled trial. BMC Geriatr. 2017, 17, 192. [CrossRef] [PubMed]

38. Nicholas, S.O.; Giang, A.T.; Yap, P.L.K. The effectiveness of horticultural therapy on older adults: A systematic review. JAMDA 2019, 20, 1351.e1-1351.e11. [CrossRef]

39. Davis, J.N.; Spaniol, M.R.; Somerset, S. Sustenance and sustainability: Maximizing the impact of school gardens on health outcomes. Public Health Nutr. 2015, 18, 2358-2367. [CrossRef] [PubMed]

40. Utter, J.; Denny, S.; Dyson, B. School gardens and adolescent nutrition and BMI: Results from a national, multilevel study. Prev. Med. 2016, 83, 1-4. [CrossRef]

41. Earle, M.D. Cultivating Health: Community Gardening as a Public Health Intervention. Master's Thesis, University of Otago, Dunedin, New Zealand. Available online: http:/ / hdl.handle.net/10523/2078 (accessed on 4 January 2021).

42. Andreotta, M.D.R.; Tapper, A.; Clough, D.; Carrera, J.S.; Sandhaus, S. Understanding the intrinsic and extrinsic motivations associated with community gardening to improve environmental public health prevention and intervention. Int. J. Environ. Res. Public Health 2019, 16, 494. [CrossRef]

43. Kou, H.; Zhang, S.; Liu, Y. Community-engaged research for the promotion of healthy urban environments: A case study of community garden initiative in Shanghai, China. Int. J. Environ. Res. Public Health 2019, 16, 4145. [CrossRef] [PubMed]

44. Leporelli, E.; Santi, G. From Psychology of Sustainability to Sustainability of Urban Spaces: Promoting a Primary Prevention Approach for Well-Being in the Healthy City Designing. A Waterfront Case Study in Livorno. Sustainability 2019, 11, 760. [CrossRef] 